\title{
Integrated disciplines and future competencies: A blueprint for ethically aligned curriculum for IT, CS, ITC \& beyond
}

\author{
Alexander Libin ${ }^{1,2}$ \\ ${ }^{1}$ Department of Medical Rehabilitation, Georgetown University, Washington, DC, USA, \\ ${ }^{2}$ Center for Advanced Research in Integrated and Digital Humanities (CARIDH), Russian \\ State University for the Humanities, Moscow, Russia
}

\begin{abstract}
Autonomous and intelligent technical systems are specifically designed to reduce the necessity for human intervention in our daily lives. In so doing, these new computer-based systems are also raising concerns about their impact on individuals and society. Because of their innovative nature, the full benefit will be obtained only if the technology is aligned with society's defined values guided by ethical principles. Through the proposed ethically aligned curriculum (ETHIKA) for computer sciences (CS) and information technology (IT) specialties we intend, therefore, to establish frameworks to guide and inform dialogue and debate around the non-technical implications, in particular related to ethical dilemmas. Hereby we understand "ethical" to go beyond universal moral constructs, such as trust, harm, good or bad, and include ethical designs for AI-based technologies, socially-oriented computer sciences, and ethical risks of digital society. As digital economy prospers, more CS/IT-professionals realize the power of education-driven intellectual capacity $\left(\operatorname{In} C^{E D}\right)$. It is hypothesized, that In $C^{E D}$ has direct impact on learning competencies of students, warranting future successful management of professional and life ethical challenges. ETHIKA elucidate, through both methodological and experimental inquiries, the impact of global digitalization and related ethical risks on learning and professional competencies in both professional CS/IT-community and the University students.
\end{abstract}

Keywords: CS/IT-community, integrated disciplines, future competencies, life-long learning, digital world, professional expertise. 


\section{Introduction: ethical design for innovative breakthrough technologies}

In the new millennium innovative digital technologies trigger more controversies then any technological advances in previous eras. The very structure of our societal processes, shaped by the computer science and its practical applications, is changing dramatically. Emerging digital society requires timely resolution of ethical dilemmas, now materialized through AI technologies and the Internet-of-Things (Schwab, 2019). The ethical component of innovative technologies already have a very specific value in digital world, resulting in emerging concepts such as CyberEthics or Digital Ethics (Libin, 2019), and AI-For-Good (ITU, 2019). Development of AI-based technologies calls for a new social contract between computer sciences (CS) community, including ITs, ICTs, programmers (aka IT specialties), mathematicians, and R\&D developers, and digital society stakeholders such as consumers, customers, users, and other participating individuals. Ethical regulations are becoming a common place for the innovations and related production process. In the same way, traditional education is transformed by new learning practices focusing not only on knowledge acquisition, but efficient knowledge implementation expressed through learning and professional competencies.

As digital technologies and digital economy prosper, more professionals realize the vast power of ethics that regulates education-driven intellectual capacity. The cumulative learning outcomes can be defined as generalized intellectual capital in education $\left(\mathrm{InC}^{\mathrm{ED}}\right)$, expressed through an algorithm comprised from four different factors: ethical reasoning, academic achievements, coping with complex professional and life situations, and digital proficiency. It is hypothesized, that $\mathrm{InC}^{\mathrm{ED}}$ has direct impact on learning competencies of students warranting future successful management of professional and life challenges.

\section{A blueprint for ethically aligned curriculum (ETHIKA) for CS/IT specialties}

The proposed ETHIKA curriculum framework addresses the existing gap in teaching ethics as an integrated disclipline for CS/IT students. An ethically aligned education process is grounded in the following learning modes:

○ Education through research mode focuses on providing a methodology and metrics for aligning AI-based technologies with digital ethics values, and also to enhance higher education with R\&D components across traditional and innovative University disciplines. This ETHIKA curriculum module explores the nature of ethical reasoning and decision-making in the context of AI technologies, through conceptual synthesis, conducted via systematic reviews, and traditional qualitative methods appropriate to the equivocal content of ethical reasoning and decisionmaking: semi-structured, key informant interviews, and focus groups. Result can 
provide materials for developing a set of tools, e.g. an Ethical Reasoning Toolbox (eREASON), further implemented to guide ethical design of innovative technologies;

- Ethical reasoning \& instructional design mode addresses implementation of critical thinking to learning process through examining moral problems and ethical dilemmas. Many models exist but prior to the development of the CyberAnthropology Moral Dilemmas (C D) Model (Libin, A. \& Libin, E., 2003) no approach specifically examined ethical reasoning in the cyberspace defined as a transformative shaping force of the human nature. The $C^{a} \mathrm{D}$ was developed from examination of the patterns of ethical problem-solving engaged in by technology naive experts from several disparate cultural traditions (see for details on a joined project - Libin, E. 2017). Technical knowledge and ethical knowledge were key inputs to reasoned decisions. Decisions were further informed by a wide range of "justifying" criteria such as professional codes, probabilities, and consequences. Acting on a decision finally, was subject to attitudes, conflicts between parties, and consequences of action.

○ CyberPsychology learning mode engages students with the science of digital humans, a recent phenomenon that emerged as a direct result of human multilevel engagement with artificially designed computer-generated reality (Libin, 2001). The CyberReality is not just a replica of our earthly world, it exists through specific physical embodiment formed by the ever-growing body of the hardware and software; psychological space, shaped by peoples' computer-mediated interactions; and societal factors defined by the impact the information makes on global society.

- Societal risks of global digitalization mode is a conceptual program focused on the global digitalization consequences for the most important areas of human life including education, professional activities, family, mental health, and social communities. Systematic efforts are needed to recognize, minimize, and, when possible, prevent societal risks accompanying the development and implementation of emerging technological innovations. Thus this ETHIK mode is mainly focused on life activities that are grounded more heavily in societal, rather than economical, industrial, or geopolitical factors. Ethical, or moral, dilemmas, serve as a focal point of building both a conceptual foundation and practical implications of risk studies as they relate to digital transformation of modern society.

\subsection{ETHIKA guiding principles}

The term "ethics" can be understood in two ways. It refers to the body of well-considered standards of right and wrong that serve as guideposts for human interaction. It also refers to 
the process of continually re-examining how personal and institutional beliefs and actions both live up to and shape those standards. In 1978, the National Commission for the Protection of Human Subjects of Biomedical and Behavioral Research issued the Belmont Report, a document defining basic ethical principles to guide the conduct of research and any kind of technological development involving human beings (National Commission..., 1978). These principles have come to be known as the three pillars of protection of human subjects in research. For the same token, those principles build the theoretical foundation of the guiding framework for the IEEE initiative of ethically aligned design (The IEEE Global initiative..., 2019).

The first principle is respect for persons, who sometimes are defined as "users of technology". This principle is grounded in a fundamental respect for human dignity to which there is virtual universal ascription. Respect for persons and their natural right of self-determination is the source of guidelines for informed consent. The second principle is beneficence, which requires that technology developers maximize the potential benefits to the users, and minimize the risks of harm. Finally, the third principle is justice, fair distribution of the benefits and burdens of research and development (R\&D), which considers the question of who receives the benefits of $R \& D$ and related products, and who bears its burdens.

Ethical dilemmas occur when principles compete. The principle of self-determinism supports the autonomy of an individual in, for instance, consenting to submit private data for public use. The vulnerability that is inherent in individuals with lower levels of digital literacy however, interferes with autonomy and has moral significance. Moreover, in persons with limited cognitive and/or social resources, one's choices are circumscribed by the demands of one's individual condition, reducing the range of choices that still support safety and related well-being. As demonstrated in the context of compliance vs. noncompliance with treatment regimens, individuals with chronic conditions have been shown to redefine themselves in juxtaposition to the conditions with which they live. This constitutes a decisional autonomy, but rationality of decisions cannot be assumed out of hand (Scanlan, Stewart, Kerridge, 2019). Beauchamp and Childress (2001) distinguish agency from autonomy with the former defined as the capacity to rationally guide one's reasoned desires into actions. If an individual with unmet physical, cognitive or social needs choose available technological innovation for the wrong reason, neither justice, nor beneficence, which promotes trust between user and technology developer, is served.

\subsection{ETHIKA curriculum implementation via outcomes modeling}

Implementing ETHIKA curriculum in real-world educational setting would result in a set of activities serving as in interface between engaged students, CS/IT community, and R\&D 
professionals. In this section we model the outcomes while building a blueprint for ETHIKA enterprises.

Education through research mode results in developing educational digital ethics modules (eETHICS) integrated with the University learning management system (LMS). A manual on tracking the University educational ethical competencies is implemented as part of L\&D (learning and development) module with the potential to be replicated nationally and internationally. Ethical online education modules developed as part of the University LMS might provide a foundation for future commercial R\&D capstone projects.

Ethical reasoning \& instructional design mode focuses on developing an ethical framework methodology (see Figure 1) enhanced with the assessment instrument and associated algorithm called an Ethical Reasoning Tool (eREASON) that is used to guide ethical design of innovative technologies.

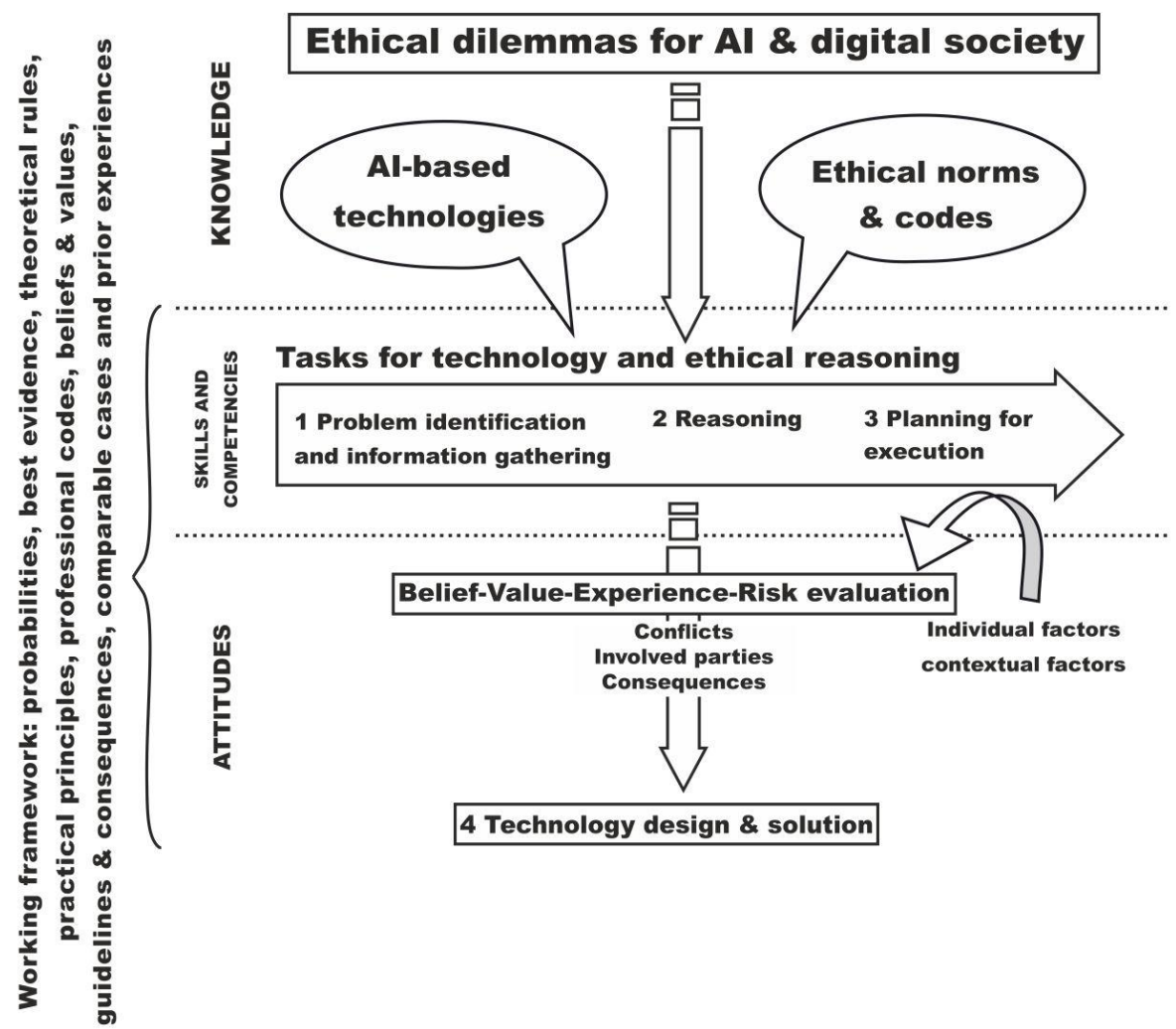

Figure 1. ETHIKA curriculum: Ethical dilemmas in digital era. 
CyberPsychology learning mode builds on educational activities based on evidence-based analytics derived from more than 3,000 peer-reviewed articles, research reports including think tanks outcomes disseminated as books and white papers, diplomas and $\mathrm{PhD}$ thesis, industry reports, and mainstream news narratives in English, Spanish, Russian, French, German, and Chinese on the subject of physiological, psychological, and sociocultural effects produced as a result of computerized technologies impact on individuals, groups and large communities. This is an ongoing crowdsourcing effort originated in 1983 and continued through network-based open source international collaboration. Four distinct patterns emerged, describing the following core elements of the CyberPsychology as a scientific inquiry, university discipline, and everyday reality framework: psychosocial competence including self-management of one's own identity, coping with negative consequence of digital immersion, CyberSecurity as it relates to personal and societal safety, and CyberEthics.

Societal risks of global digitalization mode outcome focuses of exploring the interface between 4 factors of generalized intellectual capital $\left(\mathrm{InC}^{\mathrm{ED}}\right)$ : ethical reasoning, academic achievements, coping intelligence and digital proficiency over time. Quantifying ethical risks of digital society would provide, for the first, quantified algorithm based on a multilevel modelling of digitalization risks stratified by the primary and secondary factors. Indicators of learning competencies in four areas of $\mathrm{InC}^{\mathrm{ED}}$ are explored in the context of ethic risks prediction. An experimental model provides metrics for enhancing the educational and research practices at the University.

\subsubsection{Prospects for further research $(R \& D)$ and learning \& development (L\&D)}

ETHIKA curriculum core team will capitalize on project findings and products by building a digital ethics in AI/IS international network to foster collaboration between relevant exchange programs at the participating Universities, academic and industry partners. The next phase, which will follow the completion of the described phase of ETHIKA project, would involve the development of several projects aimed at exploring the mechanisms underlying successful vs. non-successful adaptation of AI/IS technologies to everyday life, as well as routes for transferring the ongoing trends in disruptive innovations into ethically aligned $R \& D$ and $L \& D$ routes.

\section{References}

Beauchamp, Tom L. (2003). The Origins, Goals, and Core Commitments of The Belmont Report and Principles of Biomedical Ethics, in The Story of Bioethics, (Eds.) Jennifer K. Walter and Eran P. Klein, Georgetown University Press, 17-46.

Beauchamp TL, Childress JF. (2001). Principles of Biomedical Ethics, 5th ed. Oxford, UK: Oxford University Press. 
Borlongan CV, McWhirter C, Fultz-Carver C, Fitzgerald KT, Sanberg PR. (2010). The case for an ethics research consortium for emerging technologies: Public perception of stem cell research and development. Technol Innov.12:21-28.

ITU. AI for Good Global Summit 2019 Report. ITU (Report). Retrieved 23 January 2020: https://itu.foleon.com/itu/aiforgood2019/summit-highlights/

Libin, A. (2019). Cyber Ethics, Education and Security: Serving Humanity with Values. Workshop presnted at the 10th World Summit on the Information Society (WSIS) Forum at the International Telecommunications Union (ITU) in Geneva, Switzerland. Retrieved 23 January 2020:https://www.globethics.net/cyber-ethics-education-andsecurity-workshop

Libin, A. (2001). Virtual reality as a complex interactive system: A multidimensional model of person-artificial partner co-relations, in: Proc. 7th Int. Conf. Virtual Systems and Multimedia, H. Thwaites and L. Addison, (Eds.), 652-657.

Libin, A., Libin, E. (2003). Cyber-Anthropology: A Merge of Human and Technological Worlds. In: Hybrid reality: Art, Technology, Human Factors. Montreal: IOS Press, 575581. Libin, A. (2001) Complex

Libin,E. (2017). Coping Intelligence: Efficient Life Stress Management. Front. Psychol. 8:302. doi: 10.3389/fpsyg.2017.00302

National Commission for the Protection of Human Subjects of Biomedical and Behavioral Research, Department of Health, Education and Welfare (DHEW) (30 September 1978). The Belmont Report. Washington, DC: United States Government Printing Office.

Scanlan, C.L, Stewart,C., Kerridge,I. (2019). Consent in the face of death. Internal medician journal. 49 (1), 108-110. https://doi.org/10.1111/imj.14173

Schwab K. (2019). Our global system has spun out of control. Here's how to rebalance it. [Internet]. Retrieved 23 January 2020: https://www.weforum.org/agenda/2019/02/howto-rebalance-our-global-system/.

The IEEE Global Initiative on Ethics of Autonomous and Intelligent Systems. (2019). Retrived 23 January 2020: https://standards.ieee.org/content/dam/ieeestandards/standards/web/documents/other/ead1e.pdf 